\title{
Ultrasonographic characterization of lingual structures pertinent to oral, periodontal, and implant surgery
}

\author{
Shayan Barootchi ${ }^{1}$ (D) | Hsun-Liang Chan ${ }^{1}$ (D) | Sharon S. Namazi ${ }^{2}$ | Hom-Lay Wang ${ }^{1}$ (D) | \\ Oliver D. Kripfgans ${ }^{3,4}$
}

${ }^{1}$ Department of Periodontics \& Oral Medicine, University of Michigan School of Dentistry, Ann Arbor, MI, USA

${ }^{2}$ Division of Anatomy, Department of Surgery, University of Michigan Medical School, Ann Arbor, Michigan

${ }^{3}$ Department of Biomedical Engineering, College of Engineering, Ann Arbor, Michigan

${ }^{4}$ Department of Radiology, University of Michigan Medical School, Ann Arbor, Michigan

\section{Correspondence}

Hsun-Liang Chan, Department of Periodontics and Oral Medicine, University of Michigan School of Dentistry, Ann Arbor, MI.

Email: hlchan@umich.edu

\section{Funding information}

The study was supported by grants from the Delta Dental Foundation (PAF01878), the Osteology Foundation (PAF06301), Department of Periodontics and Oral Medicine Clinical Research Supplemental Research Grant, School of Dentistry Research Collaborative Award (U054647) and a NIDCR grant (1R21DE027765).

\begin{abstract}
Objectives: Increased applications of ridge augmentation in the lingual posterior mandible call for an urgent need to study its anatomy. Therefore, our first aim was to validate ultrasound in measuring the mandibular lingual structures in human cadavers. Secondarily, to test its feasibility in imaging the lingual nerve in live humans.

Materials and methods: Nine fresh un-embalmed fully/partially edentulous cadaver heads were utilized for aim 1. Three areas in the lingual mandible were imaged (mandibular premolar, molar, and retromolar). Immediately after, biopsies were harvested from each site. The thickness of the mucosa, mylohyoid muscle, and lingual nerve diameter was measured via ultrasound and statistically compared to histology. Similarly, the lingual nerve in live humans was also imaged.

Results: None of the differences between the ultrasound and histology measurements reached statistical significance $(p>.05)$. The mean mucosal thickness via ultrasound and histology was $1.45 \pm 0.49$ and $1.39 \pm 0.50 \mathrm{~mm}, 5 \mathrm{~mm}$ lingual to the mylohyoid muscle attachment. At $10 \mathrm{~mm}$ beyond the attachment, the ultrasound and histologic values were $1.54 \pm 0.48$ and $1.37 \pm 0.49$, respectively. The mean muscle thickness measured via ultrasound and histology was $2.31 \pm 0.56$ and $2.25 \pm 0.47 \mathrm{~mm}$, at the $5 \mathrm{~mm}$ distance. At the $10 \mathrm{~mm}$ distance, the measurements were $2.46 \pm 0.56$ and $2.36 \pm 0.5 \mathrm{~mm}$, respectively. The mean ultrasonic lingual nerve diameter was $2.38 \pm 0.44 \mathrm{~mm}$, versus $2.43 \pm 0.42 \mathrm{~mm}$, with histology. The lingual nerve diameter on 19 live humans averaged to $2.01 \pm 0.35 \mathrm{~mm}(1.4-3.1 \mathrm{~mm})$.

Conclusions: Within its limitations, ultrasound accurately measured mandibular lingual soft tissue structures on cadavers, and the lingual nerve on live humans.

KEYWORDS

alveolar ridge, anatomy, dental implant, diagnosis, ultrasonography
\end{abstract}

\section{1 | INTRODUCTION}

Clinicians are constantly faced with management of complex surgical cases requiring advanced and extensive tissue management. Successful management of these clinical scenarios for periodontal, oral surgery, or implant indications relies on a profound knowledge of the anatomical structures (Greenstein, Cavallaro, Romanos, \& Tarnow, 2008; Tavelli, Barootchi, Namazi, et al., 2019; Tavelli, Barootchi, Ravida, Oh, \& Wang, 2019). In particular, due to an increasing demand for augmenting atrophic posterior mandible and 
subsequent implant rehabilitation (Urban et al., 2017), a firm understanding of the biological structures in this region cannot be overemphasized. Surgical complications in the lingual posterior mandible may include mucosal tissue laceration, intrusion in the sublingual space, trauma to the branches of the lingual artery, and injury to the lingual nerve (Annibali, Ripari, La Monaca, Tonoli, \& Cristalli, 2009; Camargo \& Van Sickels, 2015; Greenstein et al., 2008; Isaacson, 2004; Longoni et al., 2007; Urban et al., 2017). These unfortunate adverse events may result in unfavorable bone augmentation outcomes, massive hemorrhage (Askar et al., 2019; Camargo \& Van Sickels, 2015), neurosensory disturbances, and impaired mastication function. Therefore, successful flap release and meticulous tissue management for achieving primary wound closure depend on a thorough anatomical understanding (Chan et al., 2010; Ritter et al., 2012; Urban et al., 2017, 2018).

In addition, it is now known that the quality and quantity of soft tissues greatly influence the healing of periodontal and implant procedures (Chao, Chang, Fu, Wang, \& Chan, 2015; De Bruyckere, Eghbali, Younes, De Bruyn, \& Cosyn, 2015; Fu et al., 2010; Lin, Chan, \& Wang, 2013). This determines the tissue phenotype, which is currently evaluated through visual examination and probing (De Rouck, Eghbali, Collys, De Bruyn, \& Cosyn, 2009; Eghbali, De Rouck, De Bruyn, \& Cosyn, 2009). For instance, in the management of an extraction socket, tissue phenotype has been correlated with the amount of horizontal and vertical bone resorption that occurs following immediate implant placement (Ferrus et al., 2010). Other studies have shown its phenotypic feature in correlation with peri-implant marginal bone remodeling as well (Linkevicius, Apse, Grybauskas, \& Puisys, 2009a, 2009b; SuarezLopez Del Amo, Lin, Monje, Galindo-Moreno, \& Wang, 2016). Soft tissue features are a determinant of success of ridge augmentation and should be carefully evaluated before the surgery (Chen et al., 2017).

In medicine, the use of non-ionizing ultrasound has been established and advocated for many years (Bhaskar, Chan, MacEachern, \& Kripfgans, 2018; Hoskins \& Kenwright, 2015; Moskalik et al., 1995; Oelze \& Mamou, 2016). In dentistry, its advantage for providing lowcost real-time cross-sectional images can be quite useful as it relates to providing optimal soft tissue contrast of pertinent anatomical structures and the peri-implant tissues (Bhaskar et al., 2018; Chan, Sinjab, et al., 2017; Chan et al., 2018). Additionally, ultrasound has been validated for measuring tissue thickness in different locations of the oral cavity (Chan, Sinjab, et al., 2017; Chan, Wang, Fowlkes, Giannobile, \& Kripfgans, 2017). A recent study from our group applied and validated the use of ultrasound for accurate assessment of peri-implant tissues on human cadavers in comparison with direct visual and cone-beam computed tomography (CBCT) (Chan et al., 2018). In light of an increasing importance of the lingual anatomy, for the first time, we applied our ultrasound probe prototype to characterize the lingual structures, that is, the dimensions of the mucosa, mylohyoid muscle and lingual nerve, in comparison with histology. Feasibility of ultrasound to image the lingual nerve on live human patients was also investigated.

\section{2 | MATERIAL AND METHODS}

This project was prepared in accordance with the EQUATOR guidelines Standards for Reporting Qualitative Research (SRQR) (O'Brien, Harris, Beckman, Reed, \& Cook, 2014).

\subsection{Study design of the cadaver research}

Nine fresh un-embalmed fully/partially edentulous human cadaver heads were provided by the Department of Anatomy to the Department of Periodontics and Oral Medicine of the University of Michigan. To reduce the occurrence of any structural tissue damages, all specimens were kept frozen at a controlled temperature of $-20^{\circ} \mathrm{C}$ (without formalin fixation) after harvesting from the human donors. Immediately prior to utilization for the experiments, the specimens were thawed to room temperature. For inclusion in the present research, it was required that specimens were either completely edentulous or partially edentulous particularly in the mandibular arch (past the mandibular canine). No other eligibility criteria were imposed in regard to the cadavers. This study was exempted by the University of Michigan Institutional Review Board (IRB) under the application number HUM00168533.

\subsection{Ultrasound imaging and measures}

The ultrasound equipment setups and the scanning procedures were performed by two experienced investigators ( $\mathrm{HC}$ and $\mathrm{OK}$ ) (Chan, Sinjab, et al., 2017; Chan, Wang, et al., 2017). Three distinct sites, the premolar, molar, and retromolar sites, were selected for imaging (Figure 1). The initial scan was performed at the premolar site, identified in relation to the mental foramen, followed by the molar site, measured $20 \mathrm{~mm}$ from the premolar site, and lastly the retromolar site, $15 \mathrm{~mm}$ posterior to the molar site. The distances were gauged with a periodontal probe (University of North Carolina [UNC] Probe, Hu-Friedy) accurate to the nearest $1 \mathrm{~mm}$. The ultrasound probe (L8-25; Zonare/Mindray) was placed at each selected site to obtain a cross-sectional image in DICOM format. The built-in function in the ultrasound device for spatial compounding was selected to obtain well-resolved images (ZS3 Zonare/Mindray). Acoustic coupling was achieved with the application of ultrasound gel (Aquasonic, Parker Inc.) and the use of a gel-based stand-off pad (Parker Inc.)

The captured ultrasound images were read with a commercially available software package (Osirix) to obtain thickness measurements of the mucosal, mylohyoid, and the lingual nerve. At each site, the thickness of the mucosa and the mylohyoid muscle were measured at two distinct locations, 5 and $10 \mathrm{~mm}$ distances lingual to the muscle attachment to the mandible. In addition to the stated measurements, at the retromolar site, the lingual nerve diameter was also obtained. All measurements were carried out by a single calibrated examiner (SB) with a built-in device caliper 


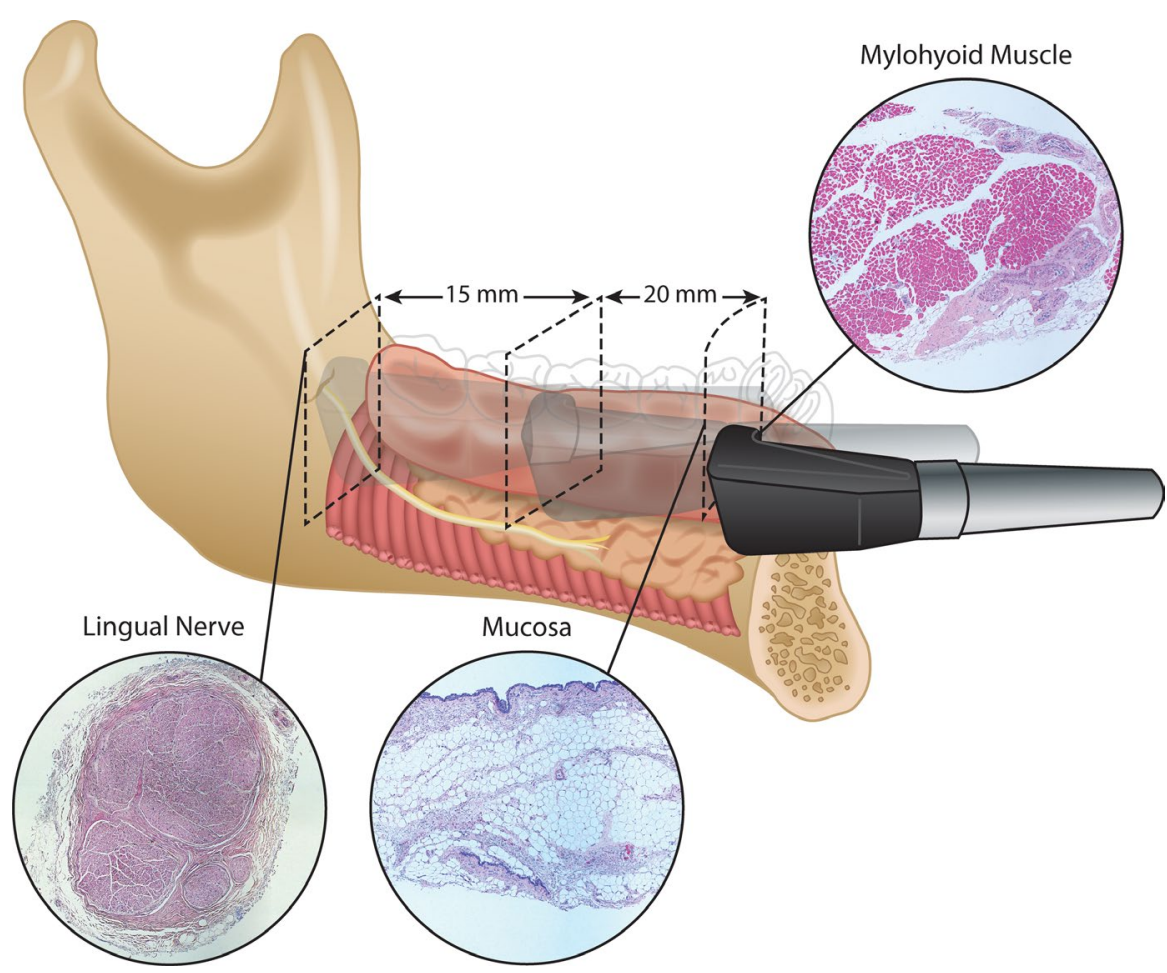

FIGURE 1 Schematic illustration of the measurements performed on ultrasound and histology on the fresh human cadaveric specimens

accurate to $0.01 \mathrm{~mm}$. The examiner calibration was performed, by measuring 10 random samples by the senior investigator $(\mathrm{HC})$ and the assessment of accuracy and reproducibility in measurements by the chosen examiner (SB) to reach an agreement value of at least 0.86 .

\section{3 | Biopsy sample collection and measurements}

Immediately after the ultrasound images were captured from each cadaver head, a biopsy sample from the same imaged sites was collected by an operator with expertise in cadaveric tissue handling and biopsy collection (SN) from the University of Michigan Anatomical Department of the Medical School. From each site, two samples, the mucosa and muscle tissues, were carefully collected. From the retromolar area, a cross-sectional slice of the lingual nerve was also obtained (as imaged with the ultrasound). All collected samples were promptly placed in $10 \%$ formalin and sent to the Histology Core at the University of Michigan Health System, Department of Pathology, Immunohistochemistry Laboratory, where they were embedded in paraffin, and sectioned to three 5 micron-thick slices at every $5 \mathrm{~mm}$ interval from the attachment, as specifically marked at the harvesting procedure using a tissue coloring marker. Subsequently, all samples were stained with hematoxylin-eosin (H\&E).

The specimens were viewed using an E800 Microscope (Nikon Instruments Inc.) with a $2 \times$ objective to perform the measurements. Images were captured using a CoolSNAP EZ camera (Photometrics) and saved using a software (NIS-Elements Advanced, Nikon Corporation). To obtain the thickness measurements, each sample was measured at every third of the total sample length and then averaged to obtain the measurement representative of that slide. This was performed for the collected samples of the mucosa and muscle. While for the nerve measurements, the diameter of each sample was measured twice in a way that the two measurements would be perpendicular to one another and then averaged to obtain the cross-sectional (diameter) thickness of that nerve. All measurements were performed by a single calibrated examiner (SB). The software was able to conduct measurements with an accuracy $0.001 \mathrm{~mm}$. The examiner calibration was performed prior to initiation of the measurement by randomly selecting 10 samples for measurement by the senior investigator $(\mathrm{HC})$ and assessment of precision of the chosen examiner (SB) for reaching an agreement value of at least 0.86 .

\subsection{Clinical feasibility of imaging the lingual nerve}

To assess the feasibility of imaging the lingual nerve with ultrasound, the second part of this study consisted of recruitment of healthy adult patients. The live human investigation part of the current study was approved by the Institutional Review Board for Human Studies (HUM00139630). The study was conducted at the Graduate Periodontal Clinic, Department of Periodontology and Oral Medicine, University of Michigan. It was conducted according to the principles embodied in the Helsinki Declaration of 1975 , as revised in $\mathbf{2 0 0 0}$ for biomedical research involving human subjects. The device setups and the scanning protocol followed the abovementioned methods. One experienced examiner $(\mathrm{HC})$ performed the scanning of the lingual nerve; while the other examiner (OK) operated the scanning machine. Acquired ultrasound images were saved 
in DICOM files and interpreted with the same commercially available software (Osirix). The lingual nerve dimension was measured with the built-in caliper accurate to $0.01 \mathrm{~mm}$.

\section{5 | Data management and statistical analysis}

All recorded measurements were entered into a spread sheet and checked for entry errors. For cadaverous data, descriptive statistics were used for qualitative presentation of the ultrasound and histology measurements by computation of means and standard deviations. To test the presence of statistically significant differences among the two modes of measurements, independent $t$ tests were utilized and a $p$ value threshold of .05 was set for significance. For live human data, the ultrasound lingual neve dimension was measured, presented as the mean and standard deviation. All analyses were conducted in Rstudio (Rstudio version 1.1.383; RStudio, Inc.) for Macintosh. Inter-examiner reliability calibration tests were performed with the DescTools package (Signorell, 2019).

\section{3 | RESULTS}

The lingual anatomical structures of nine human cadaver heads were imaged using ultrasound. Biopsy samples corresponding to the imaged sites were also successfully collected from every site. The means and standard deviations of obtained measurements from the ultrasound and histology were summarized in Table 1.

\section{1 | Imaging interpretation}

The mylohyoid is a hypoechoic (dark) band with relatively uniform thickness along its length (Figure 2-left). Within it is hyperechoic (white) strips. It attaches to the mandible at one end and extends apically and lingually toward the tongue. Above it is the mucosal layer and the sublingual space, containing the sublingual gland; below it is the submandibular space. The lingual nerve has its characteristic hyperechoic continuous bundles of neuronal fascicles separated from surrounding hypoechoic connective tissue (Figure 2-right). Anatomically, it lies above the mylohyoid muscle at the retromolar area. In this case, it is located superficially, just below the mucosal layer. Figure 3 depicts representative histologic images of the lingual mucosa, mylohyoid muscle, and lingual nerve.

\section{2 | Dimension comparisons}

The overall mean ultrasound mucosal thickness was $1.45 \pm 0.49 \mathrm{~mm}$ at $5 \mathrm{~mm}$ distance to the muscle attachment $(1.44 \mathrm{~mm}$ in the premolar, 1.31 in the molar, and 1.58 in the retromolar region), and $1.54 \pm 0.48 \mathrm{~mm}$ at the $10 \mathrm{~mm}$ distance to the attachment $(1.46 \mathrm{~mm}$ in the premolar, 1.35 in the molar, and $1.76 \mathrm{~mm}$ in the retromolar region). The corresponding histologic mucosal thickness at the respective sites averaged to $1.39 \pm 0.51 \mathrm{~mm}$ at the $5 \mathrm{~mm}$ distance to the attachment $(1.46 \mathrm{~mm}$ in the premolar, 1.30 in the molar, and $1.44 \mathrm{~mm}$ in the retromolar region), and $1.37 \pm 0.46 \mathrm{~mm}$ at $10 \mathrm{~mm}$ distance to the attachment $(1.28,1.16$, and $1.61 \mathrm{~mm}$ in the premolar, molar, and retromolar region, respectively). The differences among the obtained values from the ultrasound compared to the biopsied samples did not reach statistical significance $(p>.05)$ when tested as a whole, and among each respective region.

In regard to the mylohyoid muscle thickness measurements, the overall ultrasound mean value was $2.31 \pm 0.56$ at $5 \mathrm{~mm}$ from the attachment $(2.03 \mathrm{~mm}$ for the premolar area, $2.59 \mathrm{~mm}$ at the molar, and $2.22 \mathrm{~mm}$ at the retromolar region), and $2.46 \pm 0.56 \mathrm{~mm}$ at $10 \mathrm{~mm}$ distance to the attachment $(2.28 \mathrm{~mm}$ at the premolar, $2.75 \mathrm{~mm}$ at the molar, and $2.33 \mathrm{~mm}$ at the retromolar area). The corresponding histologic values have an overall mean of $2.25 \pm 0.47 \mathrm{~mm}$ at the $5 \mathrm{~mm}$ distance $(2.04 \mathrm{~mm}$ for premolar, 2.46 for the molar, and 2.22 for the retromolar regions), and $2.36 \pm 0.50 \mathrm{~mm}$ at the $10 \mathrm{~mm}$ distance to the attachment $(2.23,2.56$, and $2.22 \mathrm{~mm}$ at the premolar, molar, and retromolar regions, respectively). Again, there was no

TABLE 1 Ultrasound and histologic measurements of the anatomical structures of the lingual mandible

\begin{tabular}{|c|c|c|c|c|c|c|c|}
\hline Structure & Site & \multicolumn{3}{|l|}{$5 \mathrm{~mm}$} & \multicolumn{3}{|l|}{$10 \mathrm{~mm}$} \\
\hline \multirow[t]{4}{*}{ Mucosa } & Premolar & $1.448 \pm 0.402$ & $1.460 \pm 0.441$ & .957 & $1.467 \pm 0.505$ & $1.280 \pm 0.501$ & .469 \\
\hline & Molar & $1.317 \pm 0.536$ & $1.301 \pm 0.58$ & .959 & $1.358 \pm 0.391$ & $1.168 \pm 0.391$ & .391 \\
\hline & Retromolar & $1.581 \pm 0.531$ & $1.440 \pm 0.512$ & .531 & $1.761 \pm 0.512$ & $1.619 \pm 0.512$ & .521 \\
\hline & Overall & $1.453 \pm 0.496$ & $1.398 \pm 0.507$ & & $1.541 \pm 0.489$ & $1.370 \pm 0.496$ & \\
\hline \multirow{3}{*}{ Muscle } & Molar & $2.590 \pm 0.646$ & $2.461 \pm 0.466$ & .598 & $2.751 \pm 0.538$ & $2.567 \pm 0.472$ & .414 \\
\hline & Retromolar & $2.227 \pm 0.471$ & $2.225 \pm 0.475$ & .827 & $2.334 \pm 0.471$ & $2.227 \pm 0.455$ & .781 \\
\hline & Overall & $2.316 \pm 0.564$ & $2.256 \pm 0.478$ & & $2.467 \pm 0.568$ & $2.367 \pm 0.505$ & \\
\hline Nerve & Retromolar & $2.386 \pm 0.441$ & $2.432 \pm 0.423$ & .785 & & & \\
\hline
\end{tabular}

Note: All reported values are in $\mathrm{mm} \pm$ standard deviation. $p$ values are from independent $t$ tests. 


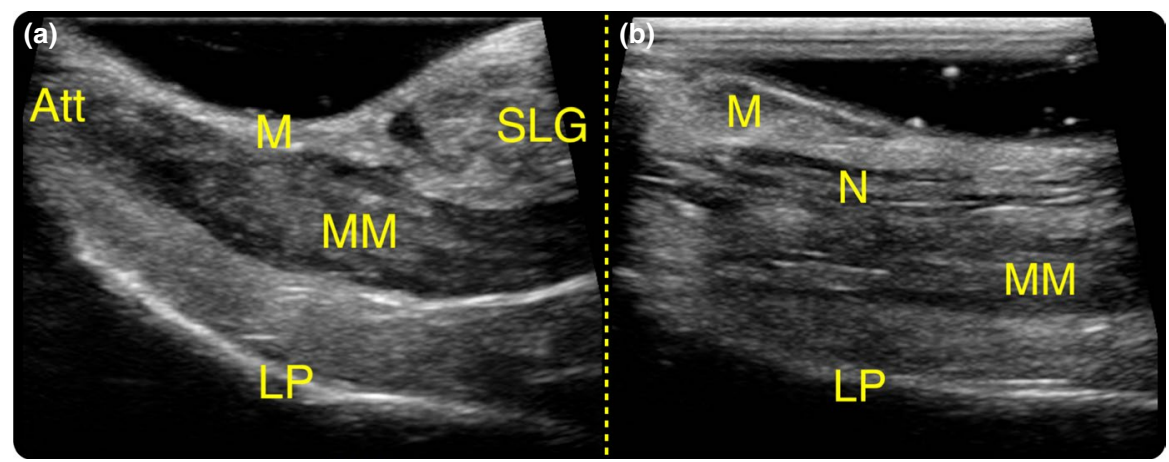

FIGURE 2 Ultrasound images of (a) the mylohyoid muscle and adjacent structures and (b) the lingual nerve. M, mucosa; SLG, sublingual gland; Att, mylohyoid muscle attachment; MM, mylohyoid muscle; LP, lingual plate of the mandible; $\mathrm{N}$, lingual nerve

(a)

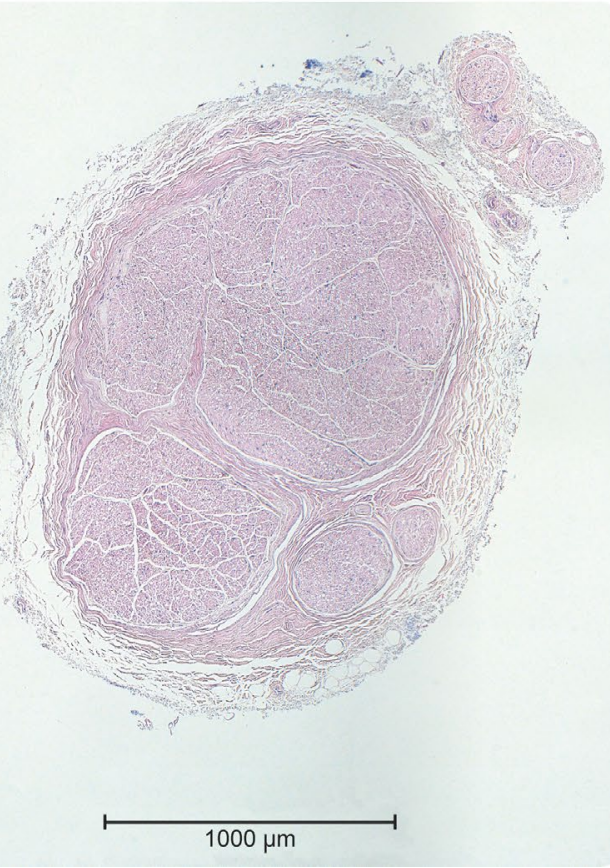

(b)

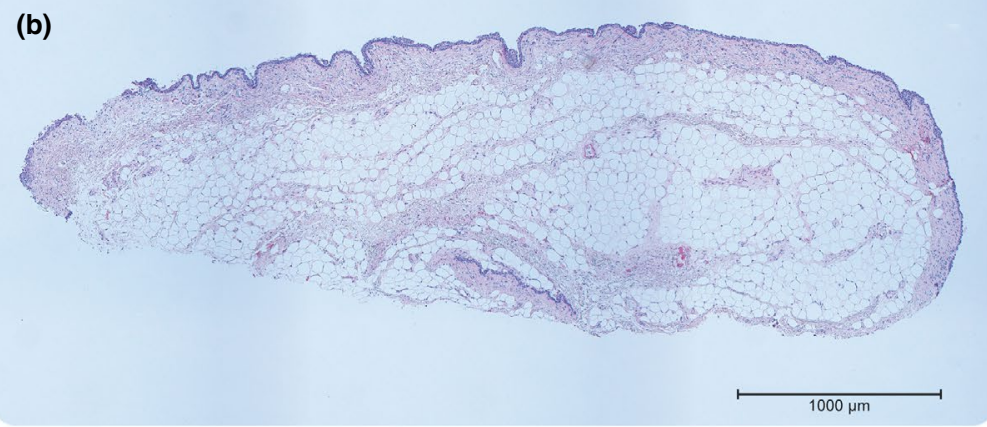

(c)

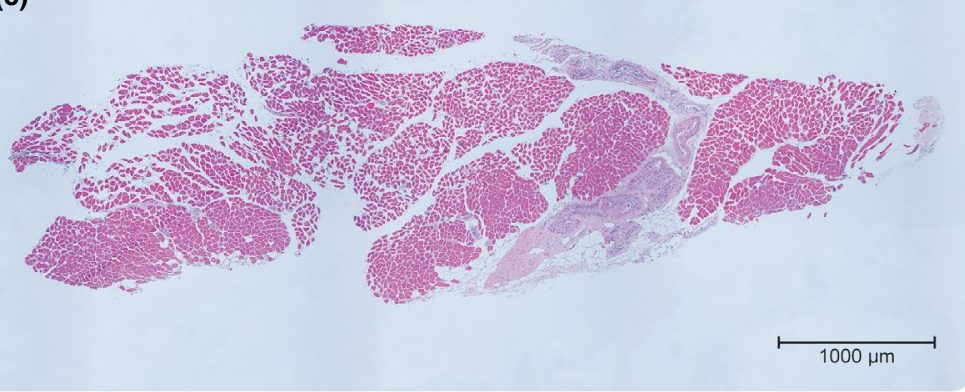

FIGURE 3 Histology images of the lingual nerve (a), mucosa (b), and the mylohyoid muscle (c)

significant differences between ultrasound and histology in any of the obtained mylohyoid muscle thickness measurements ( $p>.05$ for all comparisons).

Lastly, as for the measurements of the lingual nerve diameter, similar values were obtained via ultrasound $(2.38 \pm 0.44 \mathrm{~mm})$ and histologic assessments $(2.43 \pm 0.42 \mathrm{~mm})$ without statistically significant difference $(p>.05)$.

\section{3 | Outcomes of live human scans}

A total of 19 individuals, corresponding to 30 sites (18 on the right, and 12 on the left) were available for ultrasound imaging of the lingual nerve in the retromolar area. The mean diameter was $2.11 \pm 0.35 \mathrm{~mm}$ (ranging from 1.49 to $3.14 \mathrm{~mm}$ ). The mean values between the right and left sides were not significantly different

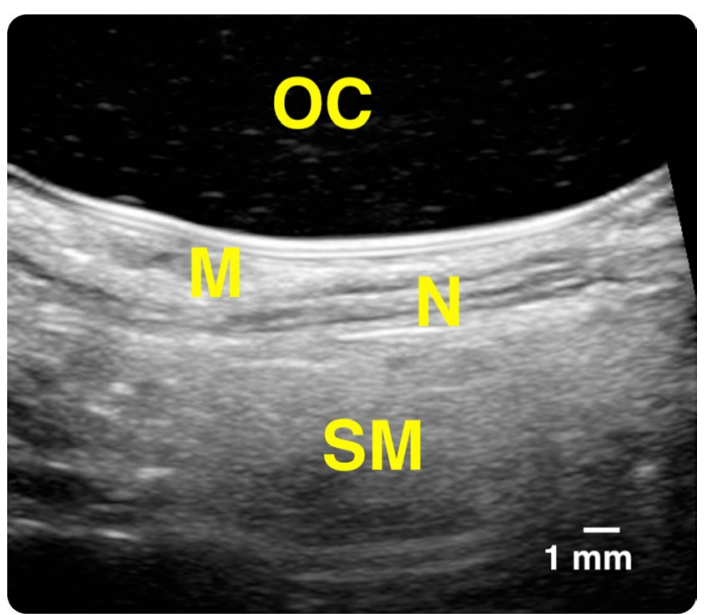

FIGURE 4 An obtained ultrasound image of the lingual nerve in a live human subject 
FIGURE 5 Scatter plot displaying the distribution of the lingual nerve diameters in live patients

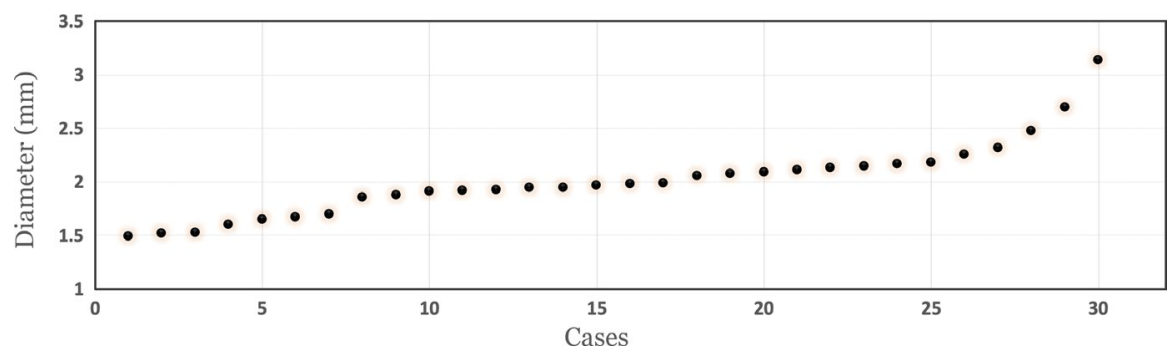

$(2.02 \pm 0.25 \mathrm{~mm}$ vs. $1.99 \pm 0.47 \mathrm{~mm}, p=.79)$. Figure 4 displays a cross-sectional image of a lingual nerve in a live human participant, and Figure 5 shows the distribution of the lingual nerve diameter.

\section{4 | DISCUSSION}

For the first time in the literature, ultrasound was found accurate in imaging the human mucosal, mylohyoid muscle, and lingual nerve because of (a) dimensional consistency with histology and the literature and (b) imaging characters in accordance with other nerves and muscles. Our study concluded ultrasound and histologic dimensions of the abovementioned structures are not statistically different. A recent study (Kikuta, Iwanaga, Kusukawa, \& Tubbs, 2019) showed the mean diameter of the lingual nerve is $2.2 \mathrm{~mm}$ (range 1.61-2.95 mm), which is in agreement with our measurements on human cadavers as well as live humans. The sheath-like hyperechoic appearance of the lingual nerve on ultrasound images is consistent with nerve fascicles. The hypoechoic band representing mylohyoid muscle is also characteristic of muscles in the rest of the body (Engel, Harn, \& Cohen, 1987; Koolstra \& van Eijden, 1999).

Anatomy of the mandibular lingual region has become more important than ever because of the popularity of performing ridge augmentation for implant placement in this region. Lingual flap releasing for achieving primary wound closure requires detachment of the lingual mucosa from the underlying mylohyoid muscle. Knowledge about the lingual mucosa thickness, sublingual salivary glands, and mylohyoid muscle attachment is key to successful lingual flap management. This study showed that the mean mucosal thickness is approximately $1.5 \mathrm{~mm}$. Histology also showed that the submucosa is mainly composed of adipose tissue. The thin dimension and loose tissue consistency reaffirmed difficulties in managing the lingual flap clinically. The mean mylohyoid muscle dimension is approximately $2.5 \mathrm{~mm}$. What may be more important is the location of the muscle attachment because it determines the degree of difficulty in releasing the lingual flap. When the attachment is high, that is, closer to the alveolar crest, flap releasing is more challenging and vice versa. Knowledge about the mylohyoid muscle location and lingual mucosa features pre-surgery could be beneficial to assess the risk of wound opening after ridge augmentation.

The lingual nerve is a branch of the mandibular nerve, providing sensory innervation to the mucous membranes of the anterior twothirds of the tongue and the lingual tissues. After entering the oral cavity, it is located at a mean distance of $3 \mathrm{~mm}$ apical to the osseous crest and $2 \mathrm{~mm}$ horizontally from the lingual cortical plate in the third molar area. (Behnia, Kheradvar, \& Shahrokhi, 2000). Nevertheless, the nerve may be situated at or above the crest of bone in $15-20 \%$ cases (Pogrel \& Goldman, 2004). Furthermore, 22\% of the time the nerve may contact the lingual cortical plate (Behnia et al., 2000). Once passing the 3rd molar, it travels mesially, apically, and medially toward the tongue. The vertical distance between the nerve and the cementoenamel junction (CEJ) of the second molar, first molar, and the second premolar was 9.6,13, and $14.8 \mathrm{~mm}$, respectively (Chan et al., 2011). Because it has superficial location in the 3rd molar region, precaution has to be exercised when performing a flap surgery in this area. A $0.6 \%-2 \%$ incidence of lingual nerve injury has been reported following third molar extraction (Bataineh, 2001; Gomes, Vasconcelos, de Oliveira e Silva, \& da Silva, 2005; Gulicher \& Gerlach, 2001; Hillerup \& Stoltze, 2007; Valmaseda-Castellon, Berini-Aytes, $\&$ Gay-Escoda, 2000). Ultrasound is an optimal imaging modality for this neve because it cannot be seen on radiographs. Our group published a proof-of-principle study showing ultrasound can image the intact lingual nerve. (19) The present study with a larger sample size and application in live humans, further confirmed the accuracy of ultrasound in imaging this nerve. Earlier reports of investigating the lingual nerve, while with a different methodology, can also been noted in the literature. Olson et al. using a slightly larger ultrasound device (25 mm transducer, 10-5 MHz) analyzed the lingual nerve in nine pig cadaveric specimens, in an attempt to correctly identify an intact, partially transected or fully transected injury to the nerve (Olsen et al., 2007). Later on, Al-Amery and colleagues, using ultrasound on previously dissected and harvested lingual nerves from six human cadavers were able to visualize the bur-induced lacerations at the damaged sites (Al-Amery, Ngeow, Nambiar, \& Naidu, 2018).

Another clinical indication for locating the lingual nerve is for its block anesthesia. The most common target for local anesthesia of the lingual nerve is the pterygomandibular space. However, inadequate anesthesia of the lingual nerve is common because of unreliable landmarks (Balasubramanian et al., 2017). Exclusive lingual nerve block at the 3rd molar region could be an effective alternative because of the following advantages: (a) easier and closer access, (b) aspiration is not required because of no major vessels in this area, and (c) less chance of post-injection trismus. Visualization of the nerve with ultrasound may improve clinician confidence, increase anesthesia success rate and working time, and reduce injection quantity. Moreover, ultrasound could be a learning tool for dental students to practice lingual nerve anesthesia. 


\section{5 | CONCLUSION}

This study successfully characterizes important anatomical structures in the lingual mandible, including the mucosa, the mylohyoid muscle, and the lingual nerve with non-invasive, non-radiation, and chairside ultrasound. This novel imaging modality may become a useful tool to evaluate lingual anatomy and assess the risk of developing complications, particularly prior to a surgery.

\section{ACKNOWLEDGEMENTS}

The authors would like to thank the body donors and their families, Mr. Dean Mueller, Coordinator of the Anatomical Donations Program for preparing the specimens, Mrs. Alicia Baker, Clinical Coordinator, and Ms. Cynthia Miller, Dental Assistant, for kindly coordinating the experiment. We also give thanks to Kenneth Rieger, Multimedia Designer, the University of Michigan for his effort in the drawing of the illustration.

\section{CONFLICT OF INTEREST}

The authors do not have any financial interests, either directly or indirectly, in the products or information listed in the paper.

\section{AUTHOR CONTRIBUTIONS}

SB contributed to conception and design, drafted and critically revised the manuscript, performed the ultrasound and histology measurements, and analyzed the data; HLC contributed to conception and design, mentored the project, performed the ultrasound scans, and drafted and critically revised the manuscript; SN performed the biopsy specimens and drafted and critically revised the manuscript; HLW contributed to conception, design, and critically revised the manuscript; OK contributed to conception and design, performed the ultrasound scans, and drafted and critically revised the manuscript. All authors gave final approval and agreed to be accountable for all aspects of the work.

\section{ORCID}

Shayan Barootchi (iD) https://orcid.org/0000-0002-5347-6577

Hsun-Liang Chan iD https://orcid.org/0000-0001-5952-0447

Hom-Lay Wang (iD https://orcid.org/0000-0003-4238-1799

\section{REFERENCES}

Al-Amery, S. M., Ngeow, W. C., Nambiar, P., \& Naidu, M. (2018). A pilot study on the effects of direct contact of two different surgical burs on the cadaveric lingual nerve. International Journal of Oral and Maxillofacial Surgery, 47(9), 1153-1160. https://doi.org/10.1016/j. ijom.2018.04.013

Annibali, S., Ripari, M., La Monaca, G., Tonoli, F., \& Cristalli, M. P. (2009) Local accidents in dental implant surgery: Prevention and treatment. The International Journal of Periodontics and Restorative Dentistry, 29(3), 325-331.

Askar, H., Di Gianfilippo, R., Ravida, A., Tattan, M., Majzoub, J., \& Wang, H. L. (2019). Incidence and severity of postoperative complications following oral, periodontal, and implant surgeries: A retrospective study. Journal of Periodontology, 90(11), 1270-1278. https://doi. org/10.1002/JPER.18-0658
Balasubramanian, S., Paneerselvam, E., Guruprasad, T., Pathumai, M. Abraham, S., \& Krishnakumar Raja, V. B. (2017). Efficacy of exclusive lingual nerve block versus conventional inferior alveolar nerve block in achieving lingual soft-tissue anesthesia. Annals of Maxillofacial Surgery, 7(2), 250-255. https://doi.org/10.4103/ams. ams_65_17

Bataineh, A. B. (2001). Sensory nerve impairment following mandibular third molar surgery. Journal of Oral and Maxillofacial Surgery, 59(9), 1012-1017. https://doi.org/10.1053/joms.2001.25827

Behnia, H., Kheradvar, A., \& Shahrokhi, M. (2000). An anatomic study of the lingual nerve in the third molar region. Journal of Oral and Maxillofacial Surgery, 58(6), 649-651; discussion 652.

Bhaskar, V., Chan, H. L., MacEachern, M., \& Kripfgans, O. D. (2018) Updates on ultrasound research in implant dentistry: A systematic review of potential clinical indications. Dentomaxillofacial Radiology, 47(6), 20180076. https://doi.org/10.1259/dmfr.20180076

Camargo, I. B., \& Van Sickels, J. E. (2015). Surgical complications after implant placement. Dental Clinics of North America, 59(1), 57-72. https ://doi.org/10.1016/j.cden.2014.08.003

Chan, H. L., Benavides, E., Yeh, C. Y., Fu, J. H., Rudek, I. E., \& Wang, H. L. (2011). Risk assessment of lingual plate perforation in posterior mandibular region: A virtual implant placement study using cone-beam computed tomography. Journal of Periodontology, 82(1), 129-135. https://doi.org/10.1902/jop.2010.100313

Chan, H. L., Leong, D. J., Fu, J. H., Yeh, C. Y., Tatarakis, N., \& Wang, H. L. (2010). The significance of the lingual nerve during periodontal/implant surgery. Journal of Periodontology, 81(3), 372-377. https://doi. org/10.1902/jop.2009.090506

Chan, H. L., Sinjab, K., Chung, M. P., Chiang, Y. C., Wang, H. L., Giannobile, W. V., \& Kripfgans, O. D. (2017). Non-invasive evaluation of facial crestal bone with ultrasonography. PLoS ONE, 12(2), e0171237. https:// doi.org/10.1371/journal.pone.0171237

Chan, H. L., Sinjab, K., Li, J., Chen, Z., Wang, H. L., \& Kripfgans, O. D. (2018). Ultrasonography for noninvasive and real-time evaluation of peri-implant tissue dimensions. Journal of Clinical Periodontology, 45(8), 986-995. https://doi.org/10.1111/jcpe.12918

Chan, H. L., Wang, H. L., Fowlkes, J. B., Giannobile, W. V., \& Kripfgans, O. D. (2017). Non-ionizing real-time ultrasonography in implant and oral surgery: A feasibility study. Clinical Oral Implants Research, 28(3), 341-347. https://doi.org/10.1111/clr.12805

Chao, Y. C., Chang, P. C., Fu, J. H., Wang, H. L., \& Chan, H. L. (2015). Surgical site assessment for soft tissue management in ridge augmentation procedures. The International Journal of Periodontics and Restorative Dentistry, 35(5), e75-e83. https://doi.org/10.11607/ prd.2097

Chen, S. H., Chan, H. L., Lu, Y., Ong, S. H., Wang, H. L., Ko, E. H., \& Chang, P. C. (2017). A semi-automatic algorithm for preliminary assessment of labial gingiva and alveolar bone thickness of maxillary anterior teeth. The International Journal of Oral and Maxillofacial Implants, 32(6), 1273-1280. https://doi.org/10.11607/jomi.5566

De Bruyckere, T., Eghbali, A., Younes, F., De Bruyn, H., \& Cosyn, J. (2015). Horizontal stability of connective tissue grafts at the buccal aspect of single implants: A 1-year prospective case series. Journal of Clinical Periodontology, 42(9), 876-882. https://doi.org/10.1111/jcpe.12448

De Rouck, T., Eghbali, R., Collys, K., De Bruyn, H., \& Cosyn, J. (2009). The gingival biotype revisited: Transparency of the periodontal probe through the gingival margin as a method to discriminate thin from thick gingiva. Journal of Clinical Periodontology, 36(5), 428-433. https ://doi.org/10.1111/j.1600-051X.2009.01398.x

Eghbali, A., De Rouck, T., De Bruyn, H., \& Cosyn, J. (2009). The gingival biotype assessed by experienced and inexperienced clinicians. Journal of Clinical Periodontology, 36(11), 958-963. https://doi. org/10.1111/j.1600-051X.2009.01479.x

Engel, J. D., Harn, S. D., \& Cohen, D. M. (1987). Mylohyoid herniation: Gross and histologic evaluation with clinical correlation. Oral 
Surgery, Oral Medicine, Oral Pathology, 63(1), 55-59. https://doi. org/10.1016/0030-4220(87)90340-9

Ferrus, J., Cecchinato, D., Pjetursson, E. B., Lang, N. P., Sanz, M. \& Lindhe, J. (2010). Factors influencing ridge alterations following immediate implant placement into extraction sockets. Clinical Oral Implants Research, 21(1), 22-29. https://doi. org/10.1111/j.1600-0501.2009.01825.x

Fu, J. H., Yeh, C. Y., Chan, H. L., Tatarakis, N., Leong, D. J., \& Wang, H. L. (2010). Tissue biotype and its relation to the underlying bone morphology. Journal of Periodontology, 81(4), 569-574. https://doi. org/10.1902/jop.2009.090591

Gomes, A. C., Vasconcelos, B. C., de Oliveira e Silva, E. D., da Silva, L. C. (2005). Lingual nerve damage after mandibular third molar surgery: A randomized clinical trial. Journal of Oral and Maxillofacial Surgery, 63(10), 1443-1446. https://doi.org/10.1016/j.joms.2005.06.012

Greenstein, G., Cavallaro, J., Romanos, G., \& Tarnow, D. (2008). Clinical recommendations for avoiding and managing surgical complications associated with implant dentistry: A review. Journal of Periodontology, 79(8), 1317-1329. https://doi.org/10.1902/jop.2008.070067

Gulicher, D., \& Gerlach, K. L. (2001). Sensory impairment of the lingual and inferior alveolar nerves following removal of impacted mandibular third molars. International Journal of Oral and Maxillofacial Surgery, 30(4), 306-312. https://doi.org/10.1054/ijom.2001.0057

Hillerup, S., \& Stoltze, K. (2007). Lingual nerve injury in third molar surgery I. Observations on recovery of sensation with spontaneous healing. International Journal of Oral and Maxillofacial Surgery, 36(10), 884-889. https://doi.org/10.1016/j.ijom.2007.06.004

Hoskins, P. R., \& Kenwright, D. A. (2015). Recent developments in vascular ultrasound technology. Ultrasound, 23(3), 158-165. https://doi. org/10.1177/1742271X15578778

Isaacson, T. J. (2004). Sublingual hematoma formation during immediate placement of mandibular endosseous implants. The Journal of the American Dental Association, 135(2), 168-172. https://doi. org/10.14219/jada.archive.2004.0148

Kikuta, S., Iwanaga, J., Kusukawa, J., \& Tubbs, R. S. (2019). An anatomical study of the lingual nerve in the lower third molar area. Anatomy and Cell Biology, 52(2), 140-142. https://doi.org/10.5115/ acb.2019.52.2.140

Koolstra, J. H., \& van Eijden, T. M. (1999). Three-dimensional dynamical capabilities of the human masticatory muscles. Journal of Biomechanics, 32(2), 145-152. https://doi.org/10.1016/ S0021-9290(98)00160-2

Lin, G. H., Chan, H. L., \& Wang, H. L. (2013). The significance of keratinized mucosa on implant health: A systematic review. Journal of Periodontology, 84(12), 1755-1767. https://doi.org/10.1902/ jop.2013.120688

Linkevicius, T., Apse, P., Grybauskas, S., \& Puisys, A. (2009a). The influence of soft tissue thickness on crestal bone changes around implants: A 1-year prospective controlled clinical trial. International Journal of Oral and Maxillofacial Implants, 24(4), 712-719.

Linkevicius, T., Apse, P., Grybauskas, S., \& Puisys, A. (2009b). Reaction of crestal bone around implants depending on mucosal tissue thickness. A 1-year prospective clinical study. Stomatologija, 11(3), 83-91.

Longoni, S., Sartori, M., Braun, M., Bravetti, P., Lapi, A., Baldoni, M., \& Tredici, G. (2007). Lingual vascular canals of the mandible: The risk of bleeding complications during implant procedures. Implant Dentistry, 16(2), 131-138. https://doi.org/10.1097/ID.0b013e3180 5009d5

Moskalik, A., Carson, P. L., Meyer, C. R., Fowlkes, J. B., Rubin, J. M., \& Roubidoux, M. A. (1995). Registration of three-dimensional compound ultrasound scans of the breast for refraction and motion correction. Ultrasound in Medicine and Biology, 21(6), 769-778. https:// doi.org/10.1016/0301-5629(95)00018-M

O'Brien, B. C., Harris, I. B., Beckman, T. J., Reed, D. A., \& Cook, D. A. (2014). Standards for reporting qualitative research: A synthesis of recommendations. Academic Medicine, 89(9), 1245-1251. https://doi. org/10.1097/ACM.0000000000000388

Oelze, M. L., \& Mamou, J. (2016). Review of quantitative ultrasound: Envelope statistics and backscatter coefficient imaging and contributions to diagnostic ultrasound. IEEE Transactions on Ultrasonics, Ferroelectrics, and Frequency Control, 63(2), 336-351. https://doi. org/10.1109/TUFFC.2015.2513958

Olsen, J., Papadaki, M., Troulis, M., Kaban, L. B., O'Neill, M. J., \& Donoff, B. (2007). Using ultrasound to visualize the lingual nerve. Journal of Oral and Maxillofacial Surgery, 65(11), 2295-2300. https://doi. org/10.1016/j.joms.2007.06.647

Pogrel, M. A., \& Goldman, K. E. (2004). Lingual flap retraction for third molar removal. Journal of Oral and Maxillofacial Surgery, 62(9), 11251130. https://doi.org/10.1016/j.joms.2004.04.013

Ritter, L., Neugebauer, J., Mischkowski, R. A., Dreiseidler, T., Rothamel, D., Richter, U., ... Zoller, J. E. (2012). Evaluation of the course of the inferior alveolar nerve in the mental foramen by cone beam computed tomography. International Journal of Oral and Maxillofacial Implants, 27(5), 1014-1021.

Signorell, A. (2019). DescTools: Tools for descriptive statistics.

Suarez-Lopez Del Amo, F., Lin, G. H., Monje, A., Galindo-Moreno, P., \& Wang, H. L. (2016). Influence of soft tissue thickness on peri-implant marginal bone loss: A systematic review and meta-analysis. Journal of Periodontology, 87(6), 690-699. https://doi.org/10.1902/ jop.2016.150571

Tavelli, L., Barootchi, S., Namazi, S. S., Chan, H. L., Brzezinski, D., Danciu, T., \& Wang, H. L. (2019). The influence of palatal harvesting technique on the donor site vascular injury: A split-mouth comparative cadaver study. Journal of Periodontology, https://doi.org/10.1002/ JPER.19-0073. [Epub ahead of print].

Tavelli, L., Barootchi, S., Ravida, A., Oh, T. J., \& Wang, H. L. (2019). What is the safety zone for palatal soft tissue graft harvesting based on the locations of the greater palatine artery and foramen? A systematic review. Journal of Oral and Maxillofacial Surgery, 77(2), 271.e1-271.e9. https://doi.org/10.1016/j.joms.2018.10.002

Urban, I. A., Monje, A., Wang, H. L., Lozada, J., Gerber, G., \& Baksa, G. (2017). Mandibular regional anatomical landmarks and clinical implications for ridge augmentation. The International Journal of Periodontics and Restorative Dentistry, 37(3), 347-353. https://doi. org/10.11607/prd.3199

Urban, I., Traxler, H., Romero-Bustillos, M., Farkasdi, S., Bartee, B., Baksa, G., \& Avila-Ortiz, G. (2018). Effectiveness of two different lingual flap advancing techniques for vertical bone augmentation in the posterior mandible: a comparative, split-mouth cadaver study. The International Journal of Periodontics and Restorative Dentistry, 38(1), 35-40. https://doi.org/10.11607/prd.3227

Valmaseda-Castellon, E., Berini-Aytes, L., \& Gay-Escoda, C. (2000). Lingual nerve damage after third lower molar surgical extraction. Oral Surgery, Oral Medicine, Oral Pathology, Oral Radiology and Endodontics, 90(5), 567-573. https://doi.org/10.1067/moe.2000.110034

\section{SUPPORTING INFORMATION}

Additional supporting information may be found online in the Supporting Information section.

How to cite this article: Barootchi S, Chan H-L, Namazi SS, Wang H-L, Kripfgans OD. Ultrasonographic characterization of lingual structures pertinent to oral, periodontal, and implant surgery. Clin Oral Impl Res. 2020;31:352-359. https://doi. org/10.1111/clr.13573 